\title{
Prognosis in Patients with Non-Small Cell Lung Cancer Who Received Erlotinib Treatment and Subsequent Dose Reduction due to Skin Rash
}

\author{
Naoki Takashima ${ }^{a}$ Tomoki Kimura $^{\mathrm{b}}$ Naohiro Watanabe ${ }^{\mathrm{b}}$ Takumi Umemura $^{\mathrm{a}}$ \\ Shinya Katsuno ${ }^{a}$ Keiko Arakawa ${ }^{a}$ Masahiro Fukatsu ${ }^{a}$ Naoto Nakamura $^{a}$ \\ Osamu Nishiyama ${ }^{c}$ Kensuke Kataoka $^{\mathrm{b}}$ Yasuhiro Kondoh ${ }^{\mathrm{b}}$ Hiroyuki Taniguchi $^{\mathrm{b}}$ \\ ${ }^{a}$ Department of Pharmacy, ${ }^{b}$ Department of Respiratory Medicine and Allergy, Tosei General Hospital, Seto, Aichi, \\ 'Department of Respiratory Medicine and Allergology, Kinki University School of Medicine, Osaka-sayama, Osaka, Japan
}

\section{Keywords}

Dose reduction - Erlotinib - Non-small cell lung cancer . Skin rash

\section{Summary}

Background: Severe skin rash as toxicity of erlotinib has been reported in relation to better response and survival. However, some patients require dose reduction due to skin toxicities, and their prognosis remains uncertain. We retrospectively evaluated the clinical course of nonsmall cell lung cancer patients receiving erlotinib at a reduced dose because of skin rash. Patients and Methods: Among 76 patients treated with erlotinib, 55 patients who developed skin rash severer than grade 2 were divided into 2 groups: 24 patients treated with erlotinib with dose reduction because of skin rash (dose reduction group) and 31 patients without any dose reduction (nondose reduction group). Results: The median progressionfree survival in the dose reduction and non-dose reduction groups was 341 and 70 days, respectively, and the median overall survival was 566 and 202 days, respectively $(p<0.001)$. In the dose reduction group, no smoking history, female sex, epidermal growth factor receptor gene mutation, and grade 3 skin rash were significant baseline factors. Conclusions: Patients who received erlotinib at a reduced dose following skin rash showed better survival than those without reduction. In cases of intolerable skin rash, patients may benefit from continuous treatment with a reduced dose of erlotinib.
Schlüsselwörter

Dosisreduktion · Erlotinib · Nichtkleinzelliges

Bronchialkarzinom · Hautausschlag

\section{Zusammenfassung}

Hintergrund: Schwerwiegenderer Hautausschlag als toxische Nebenwirkung von Erlotinib wurde mit einem besseren Ansprechen und längerem Überleben in Zusammenhang gebracht. Einige Patienten benötigen jedoch eine Dosisreduktion aufgrund der Hauttoxizität und ihre Prognose ist bisher ungeklärt. In einer retrospektiven Analyse haben wir den klinischen Verlauf von Patienten mit nichtkleinzelligem Lungenkarzinom, die eine Erlotinib-Behandlung mit einer Dosisreduktion aufgrund von Hautausschlag erhielten, untersucht. Patienten und Methoden: Von 76 Patienten, die mit Erlotinib behandelt wurden, entwickelten 55 einen Hautausschlag mit einem Schweregrad höher als 2. Diese wurden in 2 Gruppen aufgeteilt: 24 Patienten, die nach Erlotinib-Behandlung eine Dosisreduktion aufgrund des Hautausschlags erhielten (Dosisreduktionsgruppe), und 31 Patienten, die keine Dosisreduktion erhielten (Nicht-Dosisreduktionsgruppe). Ergebnisse: Das mediane progressionsfreie Überleben in der Dosisreduktions- und der Nicht-Dosisreduktionsgruppe betrug 341 bzw. 70 Tage und das mediane Gesamtüberleben betrug 566 bzw. 202 Tage ( $p<0,001)$. In der Dosisreduktionsgruppe waren keine Rauchervorgeschichte, weibliches Geschlecht, Mutation des epidermalen Wachstumsfaktorrezeptors und Hautausschlag Grad 3 signifikante Basislinien-Faktoren. Schlussfolgerungen: Patienten, die eine Erlotinib-Behandlung mit Dosisreduktion nach einem Hautausschlag erhielten, zeigten ein längeres Überleben als Patienten ohne Dosisreduktion. In Fällen von unerträglichem Hautausschlag könnten Patienten von einer fortgesetzten Behandlung mit einer reduzierten Erlotinib-Dosis profitieren.

Hiroyuki Taniguchi, M.D

Department of Respiratory Medicine and Allergy Tosei General Hospital

160 Nishioiwake-cho, Seto, Aichi 489-8642, Japan taniguchi@tosei.or.jp 


\section{Introduction}

Erlotinib is an oral epidermal growth factor receptor tyrosine kinase inhibitor (EGFR-TKI) that is mainly used for patients with advanced or metastatic non-small cell lung cancer (NSCLC) who have failed at least 1 prior chemotherapy regimen. As is well known, the most common adverse effect of erlotinib is skin rash. In international phase III clinical trials (BR.21) involving 485 cases, the major adverse effects of erlotinib included skin rash $(75.5 \%, \mathrm{n}=366)$, pruritus $(12.6 \%$, $\mathrm{n}=61)$, and dry skin $(12.4 \%, \mathrm{n}=60)$ [1]. In phase II clinical trials conducted in Japan (JO16565 and JO18396 trials) involving 108 cases, the major adverse effects included eruption $(98.1 \%, \mathrm{n}=106)$, dry skin $(71.3 \%, \mathrm{n}=77)$, and pruritus $(69.4 \%, n=75)[2,3]$. These skin problems have been observed more frequently than other adverse effects.

On the other hand, recent clinical trials suggest that a higher grade of rash is associated with clinical benefit [3-8]. Moreover, such toxicities due to EGFR inhibitors can be controlled while continuing treatment with the EGFR inhibitors, and patients do not necessarily need to be switched to alternative treatments [9]. Among cases of strong rash, however, there are patients who need a reduced dose for the symptomatic control of their skin rash. In such patients, reduction of the erlotinib dose can lead to reduction of symptoms, making it possible to continue treatment. This raises the question whether patients benefit from erlotinib treatment with reduced doses after interruption of treatment compared with permanent discontinuation. Few reports have evaluated the outcome of patients who received separate reductions in erlotinib dose [10]. Specifically, there are no reports, to our knowledge, that evaluate the outcome of patients who received erlotinib treatment with dose reduction owing exclusively to skin toxicities.

The purpose of the present study was to clarify the prognosis of NSCLC patients who received erlotinib treatment at reduced doses because of skin rash.

\section{Methods}

This study was approved by the Ethics Committee of Tosei General Hospital (Aichi, Japan). The subjects were 76 NSCLC patients who failed at least 1 prior chemotherapy regimen and were later treated with erlotinib (150 mg/day) from February 2008 to August 2009 in our hospital. We retrospectively examined their baseline factors, dose reductions, adverse events and efficacy from initiation of treatment until January 2011, based on medical records.

Baseline factors included the following: age, gender, performance status (PS) based on the criteria of the Eastern Cooperative Oncology Group, histological type, chemotherapeutic history, smoking history, and EGFR gene mutation (determined using the peptide nucleic acid and locked nucleic acid polymerase chain reaction clamp method). Histological types of lung cancer were defined according to the World Health Organization classification of 1999. The clinical stage of these patients was determined based on the tumor, node, metastasis (TNM) classification of the Union for International Cancer Control (UICC) [11].
Skin rash was examined according to the following factors: frequency of development, severity, timing of onset, location, and the state of the skin after dose reduction. We also examined the number of cases treated with a reduced dose of erlotinib mainly owing to skin rash. All toxicities were graded according to the Common Terminology Criteria for Adverse Events version 3.0. Erlotinib treatment was continued in patients with grades 1-2 rash unless they refused, and stopped in those with rash grade 3 until grade $\leq 2$ was reached. When the severity of rash was considered to be unacceptable for a patient, the dose of erlotinib was reduced to 100 , 75 , or $50 \mathrm{mg}$ daily, the level at which side effects were manageable. Topical steroids were used in patients with severe skin toxicities. The adjustment to the dose of erlotinib was at the discretion of each physician. To describe the dosing conditions during the period of dose reduction, the average daily dosage (total dosage of erlotinib in the period of dose reduction/duration of dose reduction) was calculated in order to obtain the overall mean value in the dose reduction group.

Response was assessed using the Response Evaluation Criteria in Solid Tumors (RECIST). Clinical benefit was defined as complete response (CR), partial response (PR), stable disease (SD), or progressive disease $(\mathrm{PD})$, and the disease control rate $(\mathrm{CR}+\mathrm{PR}+\mathrm{SD})$ and the response rate $(\mathrm{CR}+\mathrm{PR})$ were determined. Treatment response was evaluated by computed tomography (CT) scan every 4-8 weeks. The median overall survival (OS) was measured as the period from the start of erlotinib treatment to the date of death. The median progression-free survival (PFS) was measured as the period from the start of erlotinib treatment to the identifiable time to progression. Survival was assessed up to January 31, 2011. Deaths were identified by reviewing the hospital chart records. Documentation of patient survival could be obtained because all of the patients had been visiting our hospital once a month and were admitted when their condition became worse.

The median OS and PFS were analyzed using the Kaplan-Meier method. For group comparisons, the log-rank test was used. In comparing the different baseline factors between the dose reduction and non-dose

Table 1. Characteristics of all patients treated with erlotinib

\begin{tabular}{|c|c|c|}
\hline \multicolumn{3}{|l|}{ Characteristics } \\
\hline \multicolumn{3}{|l|}{ Age, years } \\
\hline Median (range) & 67 & \\
\hline$<65$ years, $\mathrm{n}$ & 28 & 36.8 \\
\hline \multirow{2}{*}{$\geq 65$ years, $n$} & 48 & 63.2 \\
\hline & $\mathrm{n}$ & $\%$ \\
\hline Number of patients & 76 & \\
\hline \multicolumn{3}{|l|}{ Gender } \\
\hline Male & 52 & 68.4 \\
\hline Female & 24 & 31.6 \\
\hline \multicolumn{3}{|l|}{ Performance status } \\
\hline 0 & 30 & 39.5 \\
\hline 1 & 28 & 36.8 \\
\hline 2 & 8 & 10.5 \\
\hline 3 & 7 & 9.2 \\
\hline 4 & 3 & 4.0 \\
\hline \multicolumn{3}{|l|}{ Histology } \\
\hline Adenocarcinoma & 63 & 82.9 \\
\hline Squamous cell carcinoma & 11 & 14.5 \\
\hline Other & 2 & 2.6 \\
\hline \multicolumn{3}{|l|}{ Prior chemotherapy } \\
\hline 1 regimen & 45 & 59.2 \\
\hline$\geq 2$ regimens & 31 & 40.8 \\
\hline \multicolumn{3}{|l|}{ Smoking status } \\
\hline Current or former & 54 & 71.1 \\
\hline Never & 22 & 28.9 \\
\hline \multicolumn{3}{|l|}{ EGFR mutation } \\
\hline Mutant & 36 & 47.4 \\
\hline Wild-type & 26 & 34.2 \\
\hline Unknown & 14 & 18.4 \\
\hline
\end{tabular}




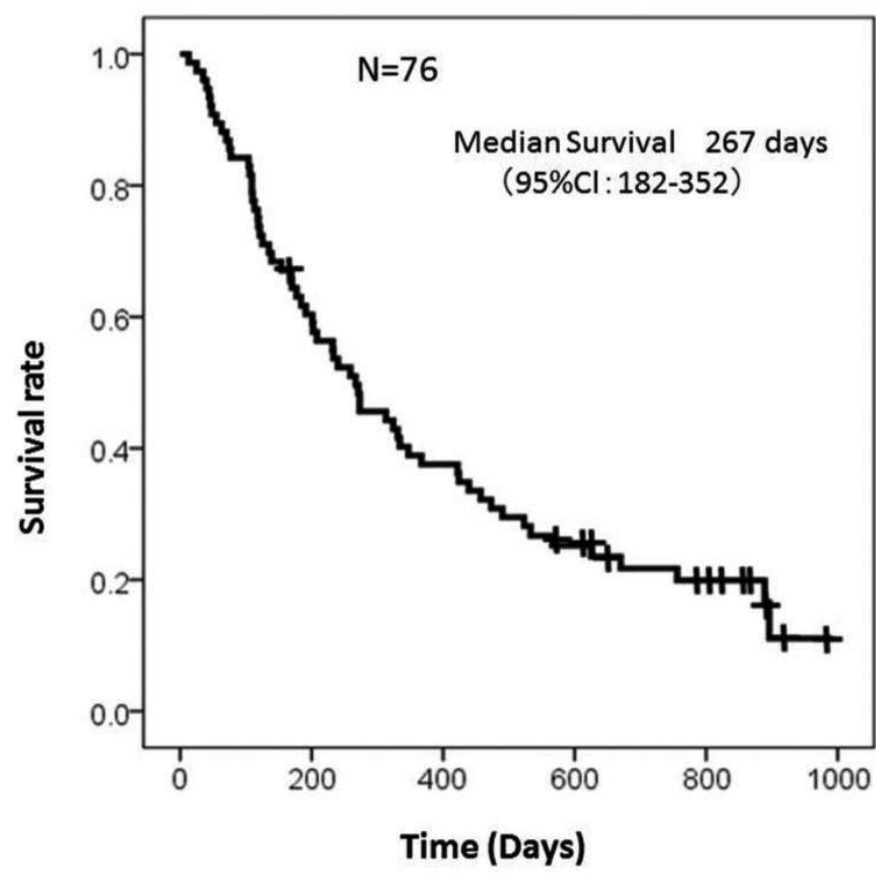

Fig. 1. Kaplan-Meier curves for OS among all patients.

reduction groups, the categorized data were analyzed with the chi-square test or Fisher's exact test. IBM SPSS Statistics 19 was used for statistical analysis. A $0.05 \%$ level of statistical significance was used for all analyses.

\section{Results}

\section{Characteristics of All Patients}

Seventy-six consecutive advanced NSCLC patients were treated with erlotinib. Their baseline characteristics are shown in table 1 . Male patients $(68.4 \%)$, patients with PS 0 or 1 $(76.3 \%)$, and current or former smokers $(71.1 \%)$ are predominant. The histological type of lung cancer in most patients was adenocarcinoma (82.9\%). All patients had advanced or recurrent disease: stage IIIB: 14, IV: 52; recurrence: 10. EGFR gene mutations were investigated in $62(81.6 \%)$ of 76 patients, and gene mutations were detected in 36 (47.4\%) patients.

\section{Tumor Response and Survival of All Patients}

Of 76 patients who were treated with erlotinib, 1 had a CR, 16 had a PR and 35 had SD, yielding a response rate of $22.4 \%$ and a disease control rate of $68.4 \%$. Survival analysis was performed on January 31, 2011, the data for which are shown in figure 1 . The median OS was 267 days (95\% confidence interval (CI) 182-352 days), and the median PFS was 95 days (95\% CI 73-117 days). 60 patients died before completion of the analysis, and 7 patients were receiving continuous erlotinib treatment at the time of analysis.

\section{Skin Rash from the Start of Erlotinb Treatment}

Most patients (69/76, 90.8\%) developed some degree of skin rash. The distribution of skin rash was as follows: grade 0 ,

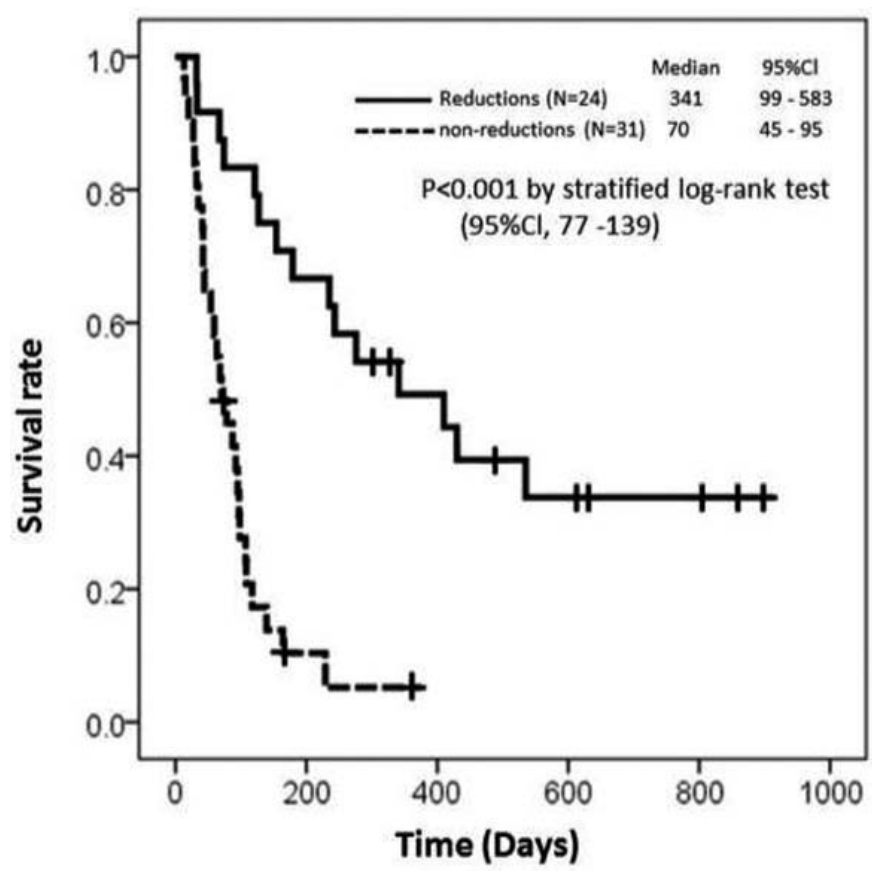

Fig. 2. Kaplan-Meier curves for PFS between reduction and non-reduction groups.

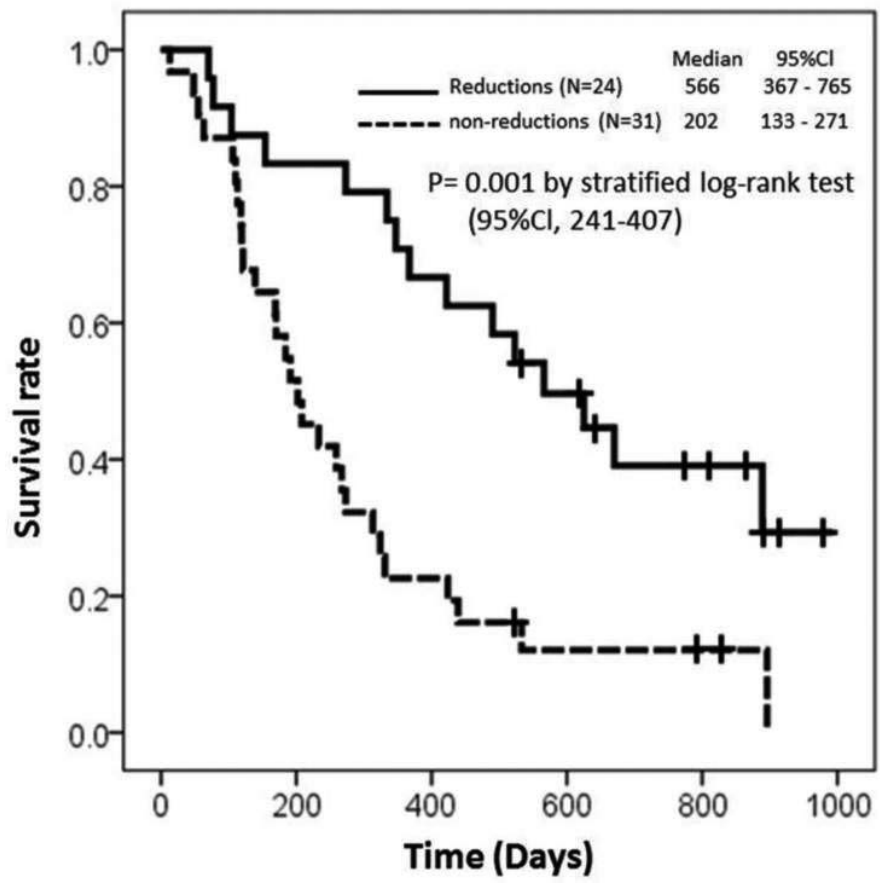

Fig. 3. Kaplan-Meier curves for OS between reduction and non-reduction groups.

$\mathrm{n}=7$; grade $1, \mathrm{n}=4$; grade $2, \mathrm{n}=50$; grade $3, \mathrm{n}=15$. Thus, 65 patients $(85.5 \%)$ developed grade $\geq 2$ skin rash. The median time of onset of skin rash was 9.8 days (range 4-43 days) from the start of treatment. Skin rash appeared frequently on the face, head/neck region, back/anterior chest, and limbs, in that order, and tended to emerge at a particularly high rate around the nose. Patients who developed skin rash of grade 


\begin{tabular}{|c|c|c|c|}
\hline \multirow[t]{2}{*}{ Characteristics } & \multicolumn{2}{|l|}{ Patients, n (\%) } & \multirow[t]{2}{*}{$\mathrm{p}$ Value } \\
\hline & Reduction $(\mathrm{n}=24)$ & Non-reduction $(\mathrm{n}=31)$ & \\
\hline Age & & & $0.584^{\mathrm{a}}$ \\
\hline$<65$ years & $8(33.3)$ & $13(41.9)$ & \\
\hline$\geq 65$ years & $16(66.7)$ & $18(58.1)$ & \\
\hline Gender & & & $0.022^{\mathrm{a}}$ \\
\hline Male & $12(50.0)$ & $25(80.6)$ & \\
\hline Female & $12(50.0)$ & $6(19.4)$ & \\
\hline Performance status & & & $1.000^{\mathrm{a}}$ \\
\hline $0-1$ & $19(79.2)$ & $24(77.4)$ & \\
\hline$\geq 2$ & $5(20.8)$ & $7(22.6)$ & \\
\hline Histology & & & $0.159^{\mathrm{b}}$ \\
\hline Adenocarcinoma & $22(91.7)$ & $23(74.2)$ & \\
\hline Other & $2(8.3)$ & $8(25.8)$ & \\
\hline Prior chemotherapy & & & $0.571^{\mathrm{a}}$ \\
\hline 1 regimen & $17(70.8)$ & $19(61.3)$ & \\
\hline$\geq 2$ regimens & $7(29.2)$ & $12(38.7)$ & \\
\hline Smoking status & & & $0.034^{\mathrm{a}}$ \\
\hline Current or former & $13(54.2)$ & $26(83.9)$ & \\
\hline Never & $11(45.8)$ & $5(16.1)$ & \\
\hline EGFR mutation & & & $0.032^{\mathrm{a}}$ \\
\hline Mutant & $15(62.5)$ & $10(32.3)$ & \\
\hline Wild-type & $3(12.5)$ & $15(48.4)$ & \\
\hline Unknown & $6(25.0)$ & $6(19.3)$ & \\
\hline Response & & & $0.013^{\mathrm{b}}$ \\
\hline $\mathrm{CR}+\mathrm{PR}+\mathrm{SD}$ & $22(91.7)$ & $19(61.3)$ & \\
\hline PD & $2(8.3)$ & $12(38.7)$ & \\
\hline Grading of rash & & & $<0.001^{\mathrm{b}}$ \\
\hline Grade 2 & $11(45.8)$ & $29(93.5)$ & \\
\hline Grade 3 & $13(54.2)$ & $2(6.5)$ & \\
\hline $\begin{array}{l}{ }^{\mathrm{a}} \chi^{2} \text { test. } \\
{ }^{\mathrm{b}} \text { Fisher's exact test. }\end{array}$ & & & \\
\hline
\end{tabular}

Table 2. Comparison of characteristics between the reduction group and the non-reduction group
2-3 had a PFS of 107 days (95\% CI 76-138 days), while those without rash or grade 1 rash had a PFS of 32 days (95\% CI $21-43$ days $)(p=0.039)$. In terms of median OS, patients with grade 2-3 skin rash had a significantly longer survival than patients without rash or grade 1 rash (313 days, 95\% CI 237388 days vs. 109 days, $95 \%$ CI 41-177 days; $\mathrm{p}=0.006)$. Among patients with grade $\geq 2$ skin rash, $98.5 \%$ were treated with a topical steroid at an early stage.

\section{Dose Reductions to Alleviate Skin Rash}

Among the 76 patients initially treated with a 150 -mg daily dose of erlotinib, 32 patients $(42.1 \%)$ required dose reductions. The main reasons for dose reduction were skin rash in 24 patients and other reasons in 8 patients. All patients who were treated with a reduced dose of erlotinib because of skin rash had developed grade $\geq 2$ skin rash. Thus, we evaluated the efficacy of dose reduction because of skin rash in patients who had developed grade $\geq 2$ skin rash. As mentioned above, 65 patients $(85.5 \%)$ developed grade $\geq 2$ skin rash. Among the 65 patients, response to erlotinib was not evaluable in 2 patients, and the reasons for dose reduction were other than skin rash in 8 patients. Therefore, the remaining 55 patients (72.4\%) comprised the study cohort. Patients who met the inclusion criteria were divided into 2 groups for comparison of results and baseline factors: the group in which the dose of erlotinib was reduced mainly owing to skin rash (dose reduction group), and the group in which reduction was not required (non-dose reduction group). The dose was reduced in 24 patients (dose reduction group) because of skin rash. Although the other 31 cases had developed skin rash severer than grade 2 , no dose reduction was required (non-dose reduction group). In the dose reduction group, the dosage was reduced 68 days (median) after initiating treatment with erlotinib. The average daily dosage after dose reduction was $83.4 \mathrm{mg}$ (range $25-100 \mathrm{mg}$ ). The dose reduction alleviated the skin rash in all patients except 1 , and as a consequence made it possible to continue erlotinib treatment.

Figures 2 and 3 show the Kaplan-Meier curves for PFS and OS in the dose reduction and non-dose reduction groups, respectively. The median PFS from the start of erlotinib treatment was 341 days (95\% CI 99-583 days) in the dose reduction group and 70 days (95\% CI 45-95 days) in the non-dose reduction group $(\mathrm{p}<0.001)$. In addition, the median PFS from the start of dose reduction was 224 days (95\% CI 0-450 days). The median OS was 566 days (95\% CI 367-765 days) in the dose reduction group and 202 days (95\% CI 133-271 days) in the non-dose reduction group ( $\mathrm{p}=0.001)$. Table 2 compares the baseline factors between the dose reduction and non-dose reduction groups. There were no significant differences in age, PS, histological type, or number of prior regimens. However, the rates of the following factors were significantly higher in the dose reduction group than in the non-dose reduction group: female sex $(\mathrm{p}=0.022)$, no smoking history $(p=0.034)$, EGFR mutation $(p=0.032)$, disease control rate $(\mathrm{p}=0.013)$, and grade 3 skin rash $(\mathrm{p}<0.001)$. The adverse event profile is shown in table 3 . Treatment-related death was 
Table 3. Erlotinib-related adverse events in either treatment group

\begin{tabular}{lrrrrrrrrrl}
\hline & \multicolumn{3}{c}{ All $(\mathrm{n}=55)$} & \multicolumn{3}{c}{ Reduction $(\mathrm{n}=24)$} & \multicolumn{3}{c}{ Non-reduction $(\mathrm{n}=31)$} \\
\cline { 2 - 10 } Grade & 2 & 3 & $\geq 4$ & 2 & 3 & $\geq 4$ & 2 & 3 & $\geq 4$ \\
\hline Rash & 40 & 15 & 0 & 11 & 13 & 0 & 29 & 2 & 0 \\
Diarrhea & 7 & 0 & 0 & 6 & 0 & 0 & 1 & 0 & 0 \\
Anorexia & 8 & 1 & 0 & 3 & 1 & 0 & 5 & 0 & 0 \\
Liver injury & 9 & 1 & 0 & 3 & 0 & 0 & 6 & 1 & 0 \\
Infection & 4 & 5 & 0 & 1 & 3 & 0 & 3 & 2 & 0 \\
Interstitial lung disease & 0 & 1 & 1 & 0 & 0 & 0 & 0 & 1 & 1 \\
\hline
\end{tabular}

Data are presented as number of patients. observed in 1 patient (interstitial lung disease) in the nondose reduction group.

\section{Discussion}

This is the first study, to our knowledge, in which the benefit of reduced doses of erlotinib was investigated among advanced NSCLC patients who required dose reduction owing exclusively to skin toxicities.

Erlotinib is an EGFR-TKI that is used in NSCLC patients who have failed at least 1 prior chemotherapy regimen, and its clinical efficacy and safety have been reported in several articles [1-3]. In the BR.21 study and 2 phase II studies, JO16565 and JO18396, the median OS was 6.7, 14.7, and 13.5 months, respectively, while the median PFS was 2.2, 2.6, and 2.5 months, respectively [1-3]. In this study, the median OS in all patients was 8.9 months, which was comparable to the results of several previous trials. Additionally, the median OS and PFS in the dose reduction group were 18.9 and 11.4 months, respectively, which were also comparable even though the patients in this group were treated with a reduced dose. Moreover, the median PFS from the start of the dose reduction was 7.5 months. Thus, the reduced doses of erlotinib resulted in sustained disease control in many patients after dose reduction. This suggests that continuous treatment with a reduced dose of erlotinib may prevent disease progression for a long period.

Severe skin rash can result in a substantial loss of quality of life and refusal to use erlotinib, although severer skin rash as a toxicity of erlotinib is reported to be related to better response and survival [3-8]. We tried reduced doses of erlotinib in patients with intolerable skin rash, with the result that some patients had sustained stabilization of disease with a markedly reduced dose. On the other hand, an unnecessary, casual reduction of erlotinib should be avoided because there is the possibility that a reduction may compromise treatment outcomes. Early dermatological supportive care before reduction is therefore important, as it may prevent considerable detrimental effects on the patients' quality of life, unnecessary dose delays, and interruptions or discontinuation of therapy. Of our patients with grade $\geq 2$ skin rash, $98.5 \%$ were treated with a topical steroid at an early stage.
Some possible reasons why dose reduction of erlotinib is effective in some patients are as follows. First, there is a difference in the approved daily dose between EGFR-TKIs. At present, 2 EGFR-TKIs, erlotinib and gefitinib, have obtained regulatory approval for NSCLC. Erlotinib is administered at its maximal tolerated dose (MTD), $150 \mathrm{mg} /$ day, while gefitinib is administered at approximately one-third of its MTD, $250 \mathrm{mg} /$ day [12]. Thus, erlotinib may have a higher biological activity than gefitinib, and reduced doses of erlotinib could have an efficacy similar to the MTD. Another possible reason is that patients with NSCLC who are highly sensitive to erlotinib may have inherent factors that are associated with better effects of erlotinib. Several clinical surrogate markers and molecular markers of survival in NSCLC patients treated with erlotinib have been reported $[7,13]$. In this study, we also compared baseline factors in the dose reduction and non-dose reduction groups. The dose reduction group comprised significantly more patients who were female, had an EGFR gene mutation, had no smoking history, and had grade 3 skin rash. Previous studies have shown that these factors are strongly associated with the effects of erlotinib [7, 13]. There is the possibility that erlotinib-related skin rash and other factors are strongly correlated with each other, although it remains unclear which of these factors is the most significant prognostic marker.

There are few published reports regarding dose reduction. Therefore, it is unclear to what extent we can reduce the dose of erlotinib without reducing its effect. In this study, the mean daily dosage after dose reduction was $83.4 \mathrm{mg}$ (range 25-100 mg). Yeo et al. [14] suggested that a dose of $25 \mathrm{mg}$ can be effective in advanced NSCLC patients with EGFR gene mutation. They concluded that future identification of the lowest dose and clinically active dose range of erlotinib will help further to personalize patient care. In another report, Lind et al. [15] reported a case of dramatic tumor response to $50 \mathrm{mg}$ erlotinib in a patient with EGFR gene mutation who developed severe rash. They concluded that dose reductions may prevent unnecessary early termination of treatment. Here, it must be noted that both reports are limited to EGFRmutated cases; there are no reports on EGFR wild-type patients who were treated with reduced doses of erlotinib. Thus, it is unclear whether dose reduction is also effective among EGFR wild-type cases. In our study, the doses were reduced 
because of skin rash in 3 out of 26 EGFR wild-type patients, and the PFS ranged from 276 to 341 days. This may be said to be a comparatively good result for EGFR wild-type cases. Although the sample size is small, it is assumed that some EGFR wild-type patients may benefit from reduced doses of erlotinib. Further studies are needed to evaluate the effect of differences in the EGFR gene mutation status on the efficacy of dose reduction of erlotinib for NSCLC patients.

The present study has several limitations. First, this study is a small, retrospective study. It will be necessary to confirm the efficacy of treatment with reduced doses of erlotinib in a large prospective study in the future. Second, this study included only Japanese patients and is a single-center analysis. Multicenter, multiregional prospective studies are needed to eliminate ethnic bias and other possible biases. Third, the non-dose reduction group included patients who had mainly $\mathrm{PD}$, which may have affected the difference in survival between the 2 groups. Patients who show a response are more likely to receive erlotinib treatment for a longer period and may have more opportunity for the development of skin rash. Fourth, the EGFR mutation status was not known for all patients. Although we tried to analyze the EGFR mutation status of all patients, some specimens were not adequate for analysis. Fifth, we did not measure the concentration of erlotinib in the serum after administration. Reduced doses of erlotinib might not have average trough concentrations high enough to exceed the inhibitory concentration, and might induce resistance in an early phase. However, we consider dose reduction to be feasible at least for patients who develop intolerable skin rash, as in our patient group. Sixth, the statistical difference in survival between the reduction group and the non-reduction group is biased by good prognostic baseline factors (female sex, never smoker, higher rate of activating EGFR mutations). A further prospective study in which relevant baseline, molecular and clinical prognostic factors are balanced between the reduction group and the non-reduction group is warranted, and multivariate analyses should be performed to evaluate the clinical efficacy of dose reduction.

In conclusion, this study showed that advanced NSCLC patients who received erlotinib treatment and subsequent dose reduction due to intolerable skin rash had a good prognosis. The reduced doses of erlotinib in cases of intolerable skin rash resulted in sustained disease control even after dose reduction.

\section{Acknowledgement}

This work was supported in part by a grant-in-aid from NPO Medise.

\section{Disclosure Statement}

None of the authors has a financial relationship with a commercial entity that has an interest in the subject of this manuscript.

\section{References}

1 Shepherd FA, Rodrigues Pereira J, Ciuleanu T, Tan EH, Hirsh V, Thongprasert S, Campos D, Maoleekoonpiroj S, Smylie M, Martins R, van Kooten M, Dediu M, Findlay B, Tu D, Johnston D, Bezjak A, Clark G, Santabárbara P, Seymour L: National Cancer Institute of Canada Clinical Trials Group: Erlotinib in previously treated non-smallcell lung cancer. N Engl J Med 2005;353:123-132.

2 Kubota K, Nishiwaki Y, Tamura T, Nakagawa K, Matsui K, Watanabe K, Hida T, Kawahara M, Katakami N, Takeda K, Yokoyama A, Noda K, Fukuoka M, Saijo N: Efficacy and safety of erlotinib monotherapy for Japanese patients with advanced non-small cell lung cancer: a phase II study. J Thorac Oncol 2008;3:1439-1445.

3 Takahashi T, Yamamoto N, Nukiwa T, Mori K, Tsuboi M, Horai T, Masuda N, Eguchi K, Mitsudomi T, Yokota S, Segawa Y, Ichinose Y, Fukuoka M, Saijo N: Phase II study of erlotinib in Japanese patients with advanced non-small cell lung cancer. Anticancer Res 2010;30:557-563.

4 Wacker B, Nagrani T, Weinberg J, Witt K, Clark G, Cagnoni PJ: Correlation between development of rash and efficacy in patients treated with the epidermal growth factor receptor tyrosine kinase inhibitor erlotinib in two large phase III studies. Clin Cancer Res 2007;13:3913-3921.

5 Pérez-Soler R: Can rash associated with HER1 EGFR inhibition be used as a marker of treatmen outcome? Oncology 2003;17:23-28.
-6 Pérez-Soler R, Chachoua A, Hammond LA, Rowinsky EK, Huberman M, Karp D, Rigas J, Clark GM, Santabárbara P, Bonomi P: Determinants of tumor response and survival with erlotinib in patients with non-small-cell lung cancer. J Clin Oncol 2004:22:3238-3247.

7 Cedrés S, Prat A, Martínez P, Pallisa E, Sala G, Andreu J, del Campo JM, Quispe I, Baselga J, Felip E: Clinical surrogate markers of survival in advanced non-small cell lung cancer (NSCLC) patients treated with second-third line erlotinib. Lung Cancer 2009;66:257-261.

8 Moore MJ, Goldstein D, Hamm J, Figer A, Hecht JR, Gallinger S, Au HJ, Murawa P, Walde D, Wolff RA, Campos D, Lim R, Ding K, Clark G, Voskoglou-Nomikos T, Ptasynski M, Parulekar W; National Cancer Institute of Canada Clinical Trials Group: Erlotinib plus gemcitabine compared with gemcitabine alone in patients with advanced pancreatic cancer: a phase III trial of the National Cancer Institute of Canada Clinical Trials Group. J Clin Oncol 2007;25:1960-1966.

9 Lynch TJ Jr, Kim ES, Eaby B, Garey J, West DP, Lacouture ME: Epidermal growth factor receptor inhibitor-associated cutaneous toxicities: an evolving paradigm in clinical management. Oncologist 2007;12:610-621.

10 Binder D, Buckendahl AC, Hübner RH, Schlattmann P, Temmesfeld-Wollbrück B, Beinert T, Suttorp N: Erlotinib in patients with advanced non- small-cell lung cancer: impact of dose reductions and a novel surrogate marker. Med Oncol 2012;29: 193-198.

11 Sobin L, Wittekind C: UICC TNM Classification of Malignant Tumors, ed 6, revised. New York, Wiley-Liss, 2002.

12 Rukazenkov Y, Speake G, Marshall G, Anderton J, Davies BR, Wilkinson RW, Mark Hickinson D, Swaisland A: Epidermal growth factor receptor tyrosine kinase inhibitors: similar but different? Anticancer Drugs 2009;20:856-866.

13 Faehling M, Eckert R, Kuom S, Kamp T, Stoiber KM, Schumann C: Benefit of erlotinib in patients with non-small-cell lung cancer is related to smoking status, gender, skin rash and radiological response but not to histology and treatment line. Oncology 2010;78:249-258.

14 Yeo WL, Riely GJ, Yeap BY, Lau MW Warner JL, Bodio K, Huberman MS, Kris MG, Tenen DG, Pao W, Kobayashi S, Costa DB: Erlotinib at a dose of $25 \mathrm{mg}$ daily for non-small cell lung cancers with EGFR mutations. J Thorac Oncol 2010;5:1048-1053.

15 Lind JS, Postmus PE, Heideman DA, Thunnissen EB, Bekers O, Smit EF: Dramatic response to lowdose erlotinib of epidermal growth factor receptor mutation-positive recurrent non-small cell lung cancer after severe cutaneous toxicity. J Thorac Oncol 2009;4:1585-1586 